\title{
PROSTATIC ABSCESS IN THE NEWBORN
}

\author{
BY \\ STEWART MANN \\ From the Department of Surgical Paediatrics, Royal Hospital for Sick Children, Glasgow
}

(RECEIVED FOR PUBLICATION OCTOBER 26, 1959)

During the past 14 months we have been able to confirm the occurrence of pyogenic infection of the prostate gland in three neonates admitted to one surgical unit of this hospital. As one case terminated fatally before we had appreciated the existence of such a clinical entity, it is desirable that it should be brought to the notice of others who may be confronted with a similar problem.

There is a current belief that the prostate has little clinical importance during infancy, and references are few. Bodian (1957) described two fatal cases of urinary retention due to fibroelastosis. Prostatic infection in older children has been reviewed extensively by Campbell (1937), and WinsburyWhite (1949) showed such a possibility in a 9-year-old boy in whom the passage of a urethral catheter produced a purulent urethral discharge, but the diagnosis was not supported by any other confirmatory findings and there was no evidence of the periprostatic haematoma formation recently reported by Williams and Martins (1960). The following instances were in newborn babies.

\section{Case Histories}

Case 1. A male child delivered at full term, weighing $6 \frac{1}{2} \mathrm{lb}$., was admitted with retention and dribbling incontinence. Catheterization was followed by an issue of almost pure pus under pressure, and, from this, penicillin insensitive Staph. aureus was subsequently isolated.

Pyuria persisted for a few days but micturition soon assumed the characteristic infant pattern, the napkins being wet intermittently, and not continuously as before. Radiographic investigation after an interval revealed no evidence of obstructive uropathy.

Case 2. A male child weighing $9 \mathrm{lb} .11 \mathrm{oz}$. was discharged from a maternity hospital following a caesarian birth, but subsequently re-admitted as the mother had noticed increasing dysuria, continuously damp napkins, and dribbling incontinence. He was 14 days old when he was admitted to this hospital with diarrhoea, bladder distension, and complete retention of urine. There was some thick pus in the urethra, and as no urine could be withdrawn by catheter, the bladder was drained by inserting a wide bore needle supra-pubically. Very gross pyuria was noted, and penicillin resistant Staph. aureus was subsequently grown from the specimen. This procedure gave considerable relief, and it seemed probable that the abscess had undergone spontaneous rupture into the bladder, but micturition did not improve, and lacked the characteristic decisiveness of infancy. Attempts to catheterize were unsuccessful as the instrument was held up in the posterior urethra, and urethrography showed a constant reduction in calibre in this area, which the radiologist reported as consistent with congenital stricture (see Figs. 1 and 2.)

This was divided by open operation, and for the past year the infant has remained well with unimpaired micturition. Pyelograms show the upper renal tracts to be within normal limits.

Case 3. A male infant, aged 3 weeks, who had been fretful from birth, was admitted to Dr. Hutchison's wards, and later transferred to the surgical side on account of increasing abdominal distension.

There was slight oedema of the lower abdominal wall, and a rather diffuse mass was palpated anteriorly on rectal examination, but the nature of this was not appreciated and a provisional diagnosis of neonatal Hirschsprung's disease was made. A distended bladder was emptied by catheter on the operating table, but unfortunately no significance was attached to this, as it is a fairly common preoperative requirement. Laparotomy revealed distension of large bowel and terminal ileum and transverse colostomy was performed. On the following day the infant died of septicaemia and an extract of the post mortem findings is as follows:

'The lower half of the small intestine and the whole of the large intestine show marked gaseous distension.

'The lungs show patchy areas of consolidation and haemorrhage.

'Both kidney pelves are moderately congested, but are not dilated, and the ureters are normal in appearance. The bladder is markedly distended. There is obvious congestion of the serosa and on opening the bladder very purulent looking urine is seen to fill the cavity. Similar purulent urine can be expressed from the urethra on compressing the bladder. At the base of the bladder a large abscess cavity measuring approximately $3 \mathrm{~cm}$. by $6 \mathrm{~cm}$. surrounds the urethra and spreads upwards behind the bladder and between it and the rectum (Fig. 3). The abscess appears to have arisen in the prostate. 


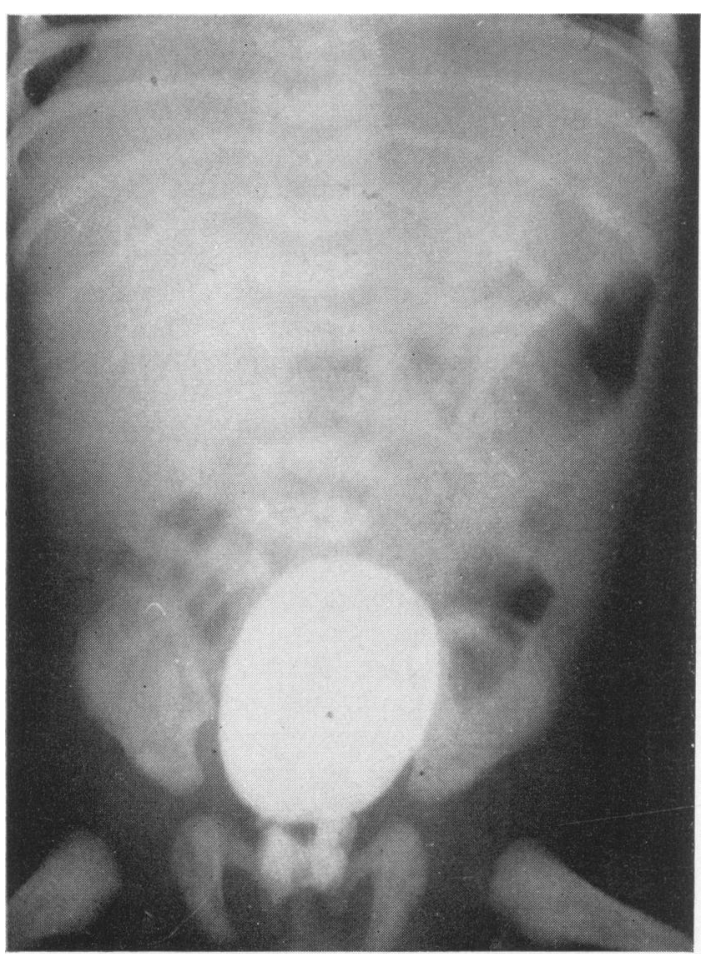

FIG. 1.

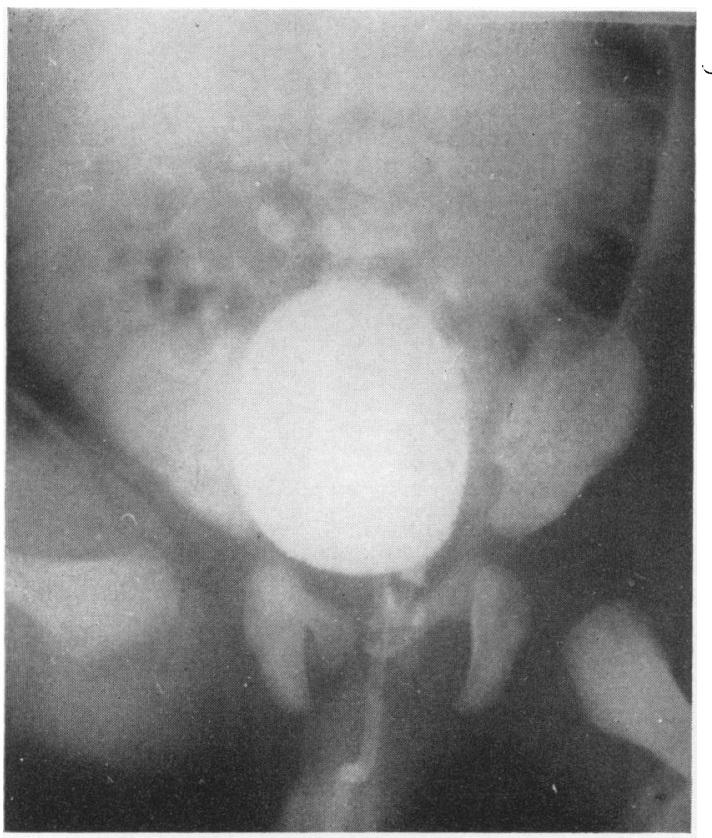

FIG. 2.

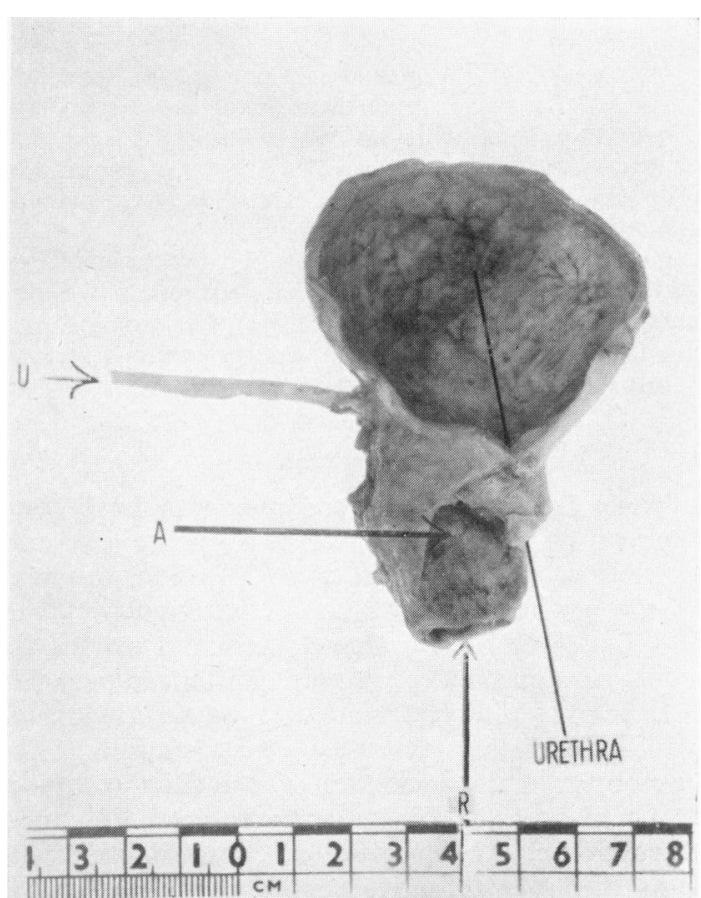

FIG. 3.

FIG. 1.-Case 2, urethrogram of prostatic abscess.

Fig. 2.-Case 2, urethrogram of residual prostatic abscess.

FIG. 3.-Case 3, abscess cavity (A) between urethra and rectum (R). Fig. 4.-Urethrogram of child's prostate to show distension by back pressure from obstruction in distal urethra.

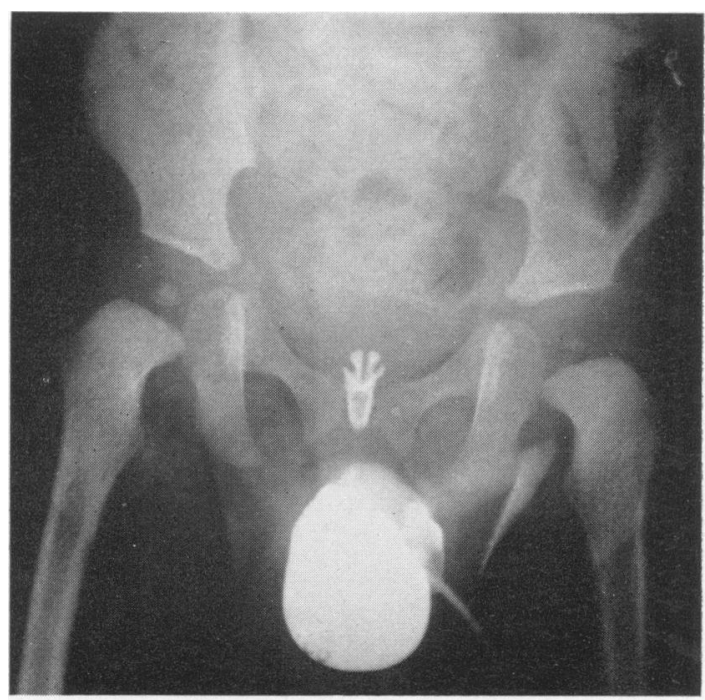

FIG. 4. 
'In the colon, ganglion cells are present in normal numbers.'

Histology. 'The abscess is chronic in type and beyond the pyogenic membrane there is a narrow rim of prostatic tissue, with pus cells in some of the adjacent glands. There is some diffuse infiltration of the bladder wall with inflammatory cells. The kidneys show early pyelonephritis.'

BACTERIOLOGY. A swab from the prostatic abscess and a piece of lung grew penicillin resistant Staph. aureus and lactose fermenting coliforms in each instance, the former being sensitive to chloromycetin and furadantin and resistant to achromycin.

\section{Discussion}

Three factors may be considered to have some bearing on the development of acute neonatal prostatitis. Firstly there is the infection, to which all the newborn are at risk. It is stated by White and Dennison (1958) that in neonatal osteitis the staphylococcus has been found resistant to penicillin in over $80 \%$ of cases admitted to the Royal Hospital for Sick Children, Glasgow, and Dennison (1959) has observed the incidence of penicillin resistance to be highest in hospital-born babies. The three cases described here were all born in maternity units and penicillin resistant staphylococcus was responsible in each.

The remaining factors may be considered to play a role in determining the location of the abscess. At birth there is the squamous metaplasia of the epithelium of the utricle, prostatic urethra and prostatic glands which undergoes regression during the first week of life (Smith, 1945). The third factor, that of obstruction to the urinary outflow, was well shown in Case 2. Potter (1952) has emphasized that congenital malformation with stasis predisposes to acute infection of the urinary system, and the effect of blockage distal to the prostate is demonstrated in the accompanying photograph (Fig. 4) where we have been able to show a dilated but otherwise normal infant prostate resulting from back pressure.

Diagnosis. There should be little difficulty in diagnosis once the condition becomes established as a clinical entity. After catheterization of a distended bladder in any male infant, one should not omit rectal examination. A cystic swelling may be felt below and in continuity with the bladder. Where rupture of the abscess occurs spontaneously, or after the use of a catheter, nothing further may be required, but urethrography should be performed, and this will show the residual abscess and indicate the site of stricture, if present. Pyogenic infection of the infant prostate may not be the rarity the literature would suggest, for spontaneous rupture into the bladder, followed by temporary pyuria, and in many cases by complete remission, is a possibility that could be overlooked. Peri-urethral abscess, secondary to infection of urethral glands has been observed in infants by White (1959) and may have originated in this manner.

Treatment. This is essentially surgical. The perineal approach to the tough distended capsule of the prostate requires special experience of paediatric urology and drainage of the infected bladder by perineal urethrostomy may be advisable, and should be continued, where necessary, until coexisting urethral stricture has been dealt with.

\section{Summary}

Three cases of acute staphylococcal prostatitis causing urinary obstruction in neonates are described. Clinical, radiograph and post mortem findings are described.

Possible causative factors are discussed and treatment indicated.

My thanks are due to Mr. Wallace Dennison who has helped me, throughout, with all cases, to Dr. Philip Rawson for radiographs and to Dr. Alistair M. MacDonald for photographs and post mortem report.

\section{REFERENCES}

Bodian, M. (1957). Some observations on the pathology of congenital 'idiopathic bladder-neck obstruction' (Marion's disease). Brit. J. Urol., 29, 393.

Campbell, M. F. (1937). Pediatric Urology, Vol. II, p. 130. Macmillan, New York.

Dennison, W. M. (1959). Personal communication.

Smith, C. A. (1945). The Physiology of the Newborn Infant, p. 261. Charles C. Thomas, Springfield, Ill., U.S.A.

Potter, Edith L. (1952). Pathology of the Fetus and the Newborn, p. 361. The Year Book Publishers, Chicago.

White, M. and Dennison, W. M. (1958). Surgery in Infancy and Childhood, p. 43. Livingstone, Edinburgh and London. (1959). Personal communication.

Williams, D. Innes and Martins, A. G. (1960). Periprostatic haematoma and prostatic abscess in the neonatal period. Arch. Dis. toma and prostatic

Winsbury-White, H. P. (1949). Some observations on bladder neck obstruction. Brit.J. Urol., 21, 342. 